progressively from 5/6 in March, 1923, to "fingers" in February, 1925. No change in the refraction of this eye could be made out.

He was treated at first with local applications of potassium iodide and dionin, and latterly with the Blache ointment of calcium and iodine, but without any apparent modification of the progress of the condition.

\title{
HELMHOLTZ'S THEORY OF ACCOMMODATION
}

BY

\author{
H. HARTRIDGE \\ KING'S COLLEGE, CAMBRIDGE
}

It is an interesting fact that the three theories which are particularly associated with the name of Helmholtz have all been receiving support as the result of recent experimental work. The trichromatic theory of colour vision, the resonance theory of hearing, and the spherical theory of accommodation one and all fell from popular favour on Helmholtz's death. The attacks of Edridge Green on the trichromatic theory, of Thomas Wrightson on the resonance theory, and of Tscherning on the spherical theory produced effects of undeniable magnitude. Now, however, these attacks have been stayed and the three theories are returning to their orginal popularity.

The history of Helmholtz's theory of accommodation may be briefly stated as follows: As is well known the physical basis of the theory requires that the crystalline lens on accommodation for near objects should become both thicker and smaller in diameter. It is a deduction from the theory that the lens, when removed from the eyeball should be in the fully accommodated state. Tscherning at first questioned every one of these statements, and, in the diagram published in his physiological optics, he showed neither a change in diameter nor in thickness. Many other ophthalmologists repeated Helmholtz's measurements and confirmed them in practically every detail. As a result Tscherning modified his position so that he showed in his diagram exhibited at the Thomas Young Oration, delivered to the Optical Society in 190\%, a change in both diameter and thickness. He still held, however, to his original contention that the lens, when removed from the eyeball should be adjusted for distant vision and not fully accommodated as Helmholtz supposed.

Of recent work on this subject a paper by Fincham (Trans. Optical Soc., Vol. XXVI, No. 5, 1924-5) is of great interest. This author, after reviewing the two rival theories in some 
detail proceeds to a determination of the optical constants for near and distant vision for the two eyes of two young men, using the most accurate methods at his command. Thus the curvature of the cornea in different meridians was measured by Drysdale's method for the determination of the curvatures of small lenses.

Fincham's principal measurements are summarized in the table given below :

\begin{tabular}{|c|c|c|c|c|c|}
\hline \multirow[b]{2}{*}{ Accommodation. } & & \multicolumn{2}{|c|}{ Case $\mathrm{H}$. } & \multicolumn{2}{|c|}{ Case $\mathbf{M}$. } \\
\hline & & +1 D. & +9 D. & $+1 \mathrm{D}$. & +9 D. \\
\hline Anterior surface lens radius $=$ & $\ldots$ & 11.62 & 6.9 & 12.0 & 5.0 \\
\hline Anterior chamber depth $=\ldots$ & $\ldots$ & 3.68 & 3.34 & 3.33 & 3.06 \\
\hline Crystalline lens thickness $=\ldots$ & $\ldots$ & 3.66 & 4.24 & 3.84 & 4.20 \\
\hline Posterior surface lens radius $=$ & $\ldots$ & 5.18 & 5.05 & 5.74 & 4.87 \\
\hline
\end{tabular}

It will be seen that in general the above measurements confirm those of Helmholtz. The interesting facts brought out concern the differences between the two cases M. and H. Whereas in Case $H$. the anterior and posterior lens surfaces suffer the greatest separation, in Case M. they change most in curvature, for the same change in accommodation. There must, therefore, be considerable individual differences in the details of the changes which bring about accommodation.

As to the details of the changes there is apparently some discrepancy between Fincham's experimental results and the explanation which he advances to account for them. Thus in Fig. 8 he shows for both cases his conclusions with regard to the eye at rest. In both the central part of the anterior lens surface is shown to be flatter than the more peripheral parts. In Fig. 9, on the other hand, is shown diagrammatically the relative capsular thickness at different parts of the lens. The capsule over the anterior surface is thinner at the centre than it is at the more peripheral portions. It is the author's hypothesis (see p. 24) that "if parts of the capsule are weaker they will be distended more readily by pressure from within and will consequently cause the surface to be more steeply curved in these parts. Thicker and stronger parts of the capsule will resist distension and so cause the surface to be flattened. Assuming the Helmholtz theory to be true, the lens in the unaccommodated state is under tension by the zonule fibres which are inserted into the capsule upon the anterior and posterior surfaces at a short distance from the equator. 
This tension upon the capsule causes it, when its strength is sufficient, to flatten the surfaces of the lens."

Now, according to Fig. 9, its strength is greater in the periphery than at the centre, and, therefore, on the author's explanation we should expect to find a more curved centre but a flatter periphery. But Fig. 8 appears to show the converse. It should be pointed out that on page 25 , line 15 , the author says: "the resultant surface would show a greater curvature in the centre than towards the periphery. Such a form was found to exist in the anterior surface of the lens in Case M. in the unaccommodated state." This statement agrees exactly with the author's conclusion. It would seem clear from this that a slip has occurred in the drawing of Fig. 8. If this is the case Fincham's results are in unequivocal agreement with Helmholtz's theory, and with those obtained by Yamada and myself (Brit. Jl. of Ophthal., Vol VI, p. 481, 1922): We found that if the crystalline lenses were removed from the cat's eyes they were in the fully accommodated state, and we concluded also that the peripheral parts of the anterior lens surface suffer a relative but not an actual flattening on accommodation. Both these conclusions are antagonistic to Tscherning's views.

I should like to complete this brief survey by expressing, firstly, my admiration for Fincham's researches, and, secondly, my hope that he will extend his researches to many more cases, not youths alone but also middle-aged. For the precise nature of the lens changes in presbyopia is practically unknown. It seems to me that the time has come to regard presbyopia as a disease and not as a normal physiological process.

\section{ANNOTATION}

\section{Lacrymal Obstruction}

Thirty years or so ago it was customary to treat our lacrymal cases in general by the old-fashioned method of probing and lavage. It is true that we gave our patients rather a bad time, but cocain was a great help as the following story shows. The writer had been in the habit of regularly passing probes on a working-class woman who habitually said nothing during the process. On only one occasion did she speak, and to the point. What she said was "Ach doctor! you're awfu' coorse the day." The cocain had been omitted. Hinc illae lacrimae. To continue, we were not satisfied with probing and there came a time when it was almost 